\title{
Time Reclaimed: Temporality and the Experience of Meaningful Work
}

\begin{abstract}
The importance of meaningful work has been identified in scholarly work across a range of disciplines. However, empirical studies remain sparse and the potential relevance of the concept of temporality, hitherto neglected even in wider sociological studies of organisations, has not been considered in terms of the light that it can shed on the experience of work as meaningful. These two disparate bodies of thought are brought together to generate new accounts of work meaningfulness through the lens of temporality. Findings from a qualitative study of workers in three occupations with ostensibly distinct temporal landscapes are reported. All jobs had the potential to be both meaningful and meaningless; meaningfulness arose episodically through work experiences that were shared, autonomous and temporally complex. Schutz's notion of the 'vivid present' emerged as relevant to understanding how work is rendered meaningful within an individual's personal and social system of relevances.
\end{abstract}

Keywords: meaningful work; temporality; time ordering; transcendence 


\section{Introduction}

Researchers within sociology, psychology and philosophy have proposed that the experience of meaningfulness is a fundamental human need and a sign of healthy psychological functioning (Frankl, 1962; Routledge et al, 2011). Work has been identified as an important potential source of meaningfulness since, as Budd (2011) has noted, work fundamentally shapes our life and establishes its basic rhythms. Although sociologists have long been concerned with understanding the various meanings that work can hold for individuals (Budd, 2011; Terkel, 1974), research on meaningfulness, in contrast, remains in its adolescence (Rosso et al, 2010). This research helps to unravel the complexity of meaningful work by showing its temporally embedded nature. The study also extends the prior sociological literature on the meaning of work (Sennett, 1998) by exploring in depth the potential meaning of work as 'meaningful', and shows that such experiences are not merely confined to professionals or craftspeople but can extend to workers in stigmatised occupations.

Lips-Wiersma and Morris (2009: 492) argue that meaningfulness is 'the subjective experience of the existential significance or purpose of life' and we draw on this, together with the work of Koltko-Rivera (2006: 306), who shows that Maslow intended self-transcendence, rather than self-actualisation, to constitute the highest form of human development, in proposing that meaningfulness arises when an individual perceives an authentic connection between their work and a broader transcendent life purpose beyond the self (Authors, 2013). This occurs in one of two potential ways; first, when individuals perceive their work impacts on others or, second, when individuals perceive their work to be in furtherance of a cause or higher purpose. This self-transcendence can invoke the greater good in terms of societal or economic benefits, or the service of a 'higher power' whether in a spiritual or religious sense, or within a non-theistic, humanist paradigm.

The notion of transcendence implies transcending not just the self, but also the here-and-now. For some while, scholars have been aware of the potential significance of theoretical time to understanding organisational phenomena and the experience of work (Langley et al., 2013); Mead for example argued as long ago as 1936 that we should 'take time seriously' (p. 300). The traditional perspective on time as linear 'clock' time parcels time into small, sequential units and thus limits our scope to understand the processes through which meaning can arise (Pedersen, 2009: 392). Time is enmeshed in the fabric of social relations so that certain tasks such as care work require not just linear time but also plural, process time for their successful completion (Davies, 1994).

This article contributes to debates about the nature and experience of work as 'meaningful' or, in contrast, 'meaningless' by considering individuals' experiences of work through a temporal lens. It draws on qualitative data to generate new theoretical insights intohow people experience their work as meaningful. The relevant literature is outlined first. The methods used to collect and analyse the data are explained next before findings are presented and their implications discussed in relation to prior studies and further research in the field.

\section{Temporality and Meaningful Work}


Although philosophers have considered fundamental questions about the distinction between 'clock' time, 'chronos', and Ricoeurian phenomenological time, 'kairos', (Ramo, 2004), these theories have rarely been applied to empirical studies within organisations. Hassard (2000) notes that time has generally been viewed as a measurable and sequential commodity of the industrial process, where the past is unrepeatable, the present transient and the future infinite and exploitable. Hence, time has been viewed as a Taylorist 'hegemonic discourse' centring on 'precision, control and discipline' ( $p$. 17). Moving to a more expanded view of time, three themes can be identified within the philosophy and sociology literatures on temporality that potentially could shed light on the experience of work as meaningful.

The first is the Durkheimian notion of the social ordering of time (Sorokin and Merton, 1937). Each individual is part of numerous social temporal orders and therefore individuals' experience of time is both subjectively constituted and intersubjectively produced through social structures and pattems (Hassard, 2000; Muzzetto, 2006), such that 'social time' is an 'expression of a collective's rhythm of activity' (Bergmann, 1992: 83). Jobs and organisations further have their own time structures and characteristic time pacing (Langley et al., 2013). For instance, some occupations such as those of artists or freelancers might have less rigid time orders, while occupations such as that of railway worker are highly time determined (Cottrell, 1939). Although for workers in some manual trades, time may be sliced into very small units with a clear boundary between work and free time (Grossin, 1974), those in other occupational groups such as the mobile hairstylists in Cohen's (2010) study may experience the permeable boundaries of the merging of work/non-work time and space. Bergmann (1992: 123) suggests that for those occupations involving a series of activities, it is impossible to talk of 'the' time structure but rather of a 'kaleidoscopic time', suggestive of time's complex, changing and potentially conflicted nature.

Temporal ordering may also arise through the interaction between humans and the objects of their work endeavours. Jalas's (2006) study of traditional wooden boating in Finland shows how the physical processes of corrosion or decay mean that material objects assume a central role in scheduling the activities of humans which, in turn, are socially configured through the 'self-artistry of slowness' ( $p$. 346) associated with historic craft practices. These practices, Jalas (2006: 361) argues, are localised and socially co-determined, often within communities of practice, thus fragmenting the notion of a universal commodification of time.

The second theme concerns the conflicted ownership and control of time, within the labour process (Hassard, 2000; Warhurst et al., 2008). Thompson (1967) asserts that it is the control of workers' time, rather than their skill and effort, which has gained primacy in efforts to extract surplus value. While it might seem that the commodification of time may be more of a concern among unskilled occupations, the symbolism of time as a currency of control may be as much of an issue for knowledge workers through explicit and tacit cultures of long hours, work intensification and performance management processes (Ell is and Taylor, 2006; Jemielniak, 2009). The organic rhythms of open-ended, unstructured 'thought-time' (Noonan, 2015: 116) or socially embedded 'process time' (Davies, 1994: 277) risk being progressively eroded through the instrumental pressures of capitalist imperatives. Workers' resistance to the alienating effects of loss of temporal control through strategies that re-ignite a sense of meaning and identity have been well documented (Simpson et al., 2014; Lopez, 2006; Sennett, 
1998). However, individually negotiated solutions to the challenges of temporal control may prove inadequate in addressing embedded social and cultural patterns (Ballard and Webster, 2009).

Finally, debates concerning the asymmetric interrelationship between past, present and future may have a bearing on the experience of meaningfulness. As Cox and Hassard (2007) have argued, time is not linear or one-dimensional, but rather may inter-penetrate in terms of factors such as pace, duration and significance; 'we experience duration in the moment, the moment just passed and the anticipated moment to come' (Cunliffe et al., 2004: 266). Time may appear to pass at a different speed depending on whether experiences are pleasant, the degree of urgency and sense of busy-ness (Cunliffe et al., 2004).

Muzzetto (2006: 15-17) explains how, according to Schutz, time is structured subjectively as well as objectively, so that meaning cannot exist in behaviour enacted in the present moment, but rather arises in the reflection on past experiences, awareness of the present experience itself and in anticipation of the future. Experiences are accumulated over time and these become interconnected through symbolic systems of relevances, such that every lived experience relates both to past and to potential future experiences. This system of relevances means that some lived experiences acquire more salience for individuals than others. Similarly, Mead argues that the present is the paramount form of temporality (Flaherty and Fine, 2001) and that human behaviour comprises events that constitute an emergent present with a past and future time horizon. The past is constantly reinterpreted from the standpoint of the present and our actions in the present continually cut into the future. Thus, from this perspective, actions in the present might become meaningful through processes of reflection that link them to past and potential future experiences (Cunliffe et al., 2004). As Tsoukas (1994: 767) argues, 'an event is never what is immediately available but also includes its contiguous past and present'. Heidegger talks of the 'lost present' (Hoy 2009: 58) as a form of inauthentic temporality that arises when people become so busy they 'lose themselves' in the everyday, thus disconnecting from past and future. Time's asymmetry means that events in the hereand-now never exist in isolation, but rather are embedded within an individual and social timescape that casts some events or experiences in a more meaningful light than others.

Although no prior empirical studies have directly considered the link between meaningful work and temporality, these themes within the sociology of time suggest two questions. How is time subjectively experienced during the enactment of meaningful work? In what sense is the transcendence of the immediate present relevant to meaningfulness?

\section{Methodology}

This article is based on the findings of 44 one hour, semi-structured face-to-face interviews with participants drawn from three occupational groups, refuse collectors, stonemasons and academics, all from within south-east England. An interpretive methodology was selected. The three occupational groups from which the data are drawn were purposively selected (Patton, 2002): refuse collectors were chosen because, perceived as a 'dirty job', those working in stigmatized occupations present particular opportunities to explore the meaningfulness of work (Davis, 1984). In contrast, the craft of stone masonry is described as 'good' work (Terkel, 1974: xi). Traditionally seen as a migrant trade (Harison, 2000), stonemasons are regarded as skilled workers and while much has been written about 
the disappearance or erosion of traditional crafts through mechanisation and organisation (Thompson and McHugh, 2009), there is a dearth of research into meaningfulness within skilled trades and none that has involved stonemasons. Academics represent a professional group with the potential to exemplify a very different temporal landscape, although the increasing time-compressionand shift to the values of 'money-time' in academic work are acknowledged (Noonan, 2015).

The interview schedule comprised four sections, covering general background information about the interviewee, their current role and past work history, their attitudes towards their work and critical incidents or stories (Bernard and Ryan, 2010) that captured experiences of meaningfulness. Each interview was digitally recorded and professionally transcribed. Demographic information about the interviewees is provided in Table 1.

\section{Table 1 here}

The data were analysed by both researchers using NVivo, coded initially using a narrative approach supplemented by emergent categories (Saldana, 2013). It was from this emergent analysis, together with iteration between the data and the relevant literature, that the underlying theme of temporality came to the fore and thematic coding was used to interrogate the data further.

\section{Findings}

\section{Occupational Timescapes}

The masons were a team of 'conservation stonemasons' who maintained a medieval cathedral. Largely, their work involved what many of them described as 'working the stone', which included 'setting out', a decorative or structural stone and its spatial setting prior to replacing or repairing it; making templates to guide the repair process; sawing large stone down to size prior to cutting or carving it to the shape of the template and fixing stones back into place. Their working day typically started at $8.30 \mathrm{am}$, finished at $4.30 \mathrm{pm}$ and occasionally involved additional hours.

The refuse collectors were based in a waste depot. The work was largely generic manual labour involving a wide range of tasks, with most tending to work in a limited number of areas. Tasks included refuse and recycling collections; street and gutter sweeping; and tipping, weighing and recording what had been collected. In the summer, the work involved some beach cleaning and, in the winter, it included shovellingsnow and gritting pavements. On some occasions, the refuse collectors were called to do 'special' collections, such as clearing fly-tipping, while some reported having to pick up dead animals (or worse). The working day started at 7am with a variable end point.

The academics all worked in universities in science disciplines and their work comprised a range of tasks including teaching, research and administration. In face of a lack of fixed working times, many talked of working very long hours. While the masons and refuse collectors generally reported relatively straightforward occupational timescapes, the academics described their work as having complex and sometimes competing temporalities relating to the various elements of their roles. 


\section{Social Ordering of Time}

Each of the three occupations had its own temporal rhythm which was associated in different ways with participants' experience of their work as meaningful. However, a common feature across the groups was that a sense of meaningfulness arose during shared ritual sor ceremonies held to mark the collective recognition of a successfully completed piece of work.

For the stonemasons, this was manifest during official unveil ing events, 'topping out ceremonies', held to open completed sections of the cathedral. These constituted shared, socially ordered moments in time when the masons experienced their work as meaningful through standing back in the presence of others and looking at the completed work in its entirety. One said, 'that experience which is at the end of a project and then the unveiling, the sense of achievement ... that's the significant event, that moment when you realise that you've saved something'. This was not an individual experience but rather a collective one, since as he explained, it is 'the part where you all look at it and go, "actually, that's not bad" and everybody else starts to say, "doesn't it look amazing?"'

For the refuse collectors, this experience tended to arise more informally during the annual Christmas party, where they 'get together and sit down and think, "well, generally, it's not been a bad year" because you get a sense that the service you're providing, most people appreciate it'. The academics described how presenting their work at a conference to an appreciative audience, or giving a wellreceived lecture, made them feel, as one described it, 'like a rock star'. As she explained, the process represents the culmination of many hours of research 'that makes it feel more real somehow, the experience didn't just happen in your head but you could communicate it to other people.' Similarly, seeing a 'PhD student successfully graduate' at the ritualistic graduation ceremony was described as a profound source of meaningfulness.

Differences emerged between the groups in terms of how the daily time pacing of work and the completion of task cycleswere linked to experienced meaningfulness. Stonemasonry is a craft learned through a three-year apprenticeship during which the masons talked about 'teaching their hands' how to 'feel through the stone'. The apprenticeship starts with the repetitive task of 'squaring the stone', where new masons spend up to six months learning how to produce a perfect cube of hand-chiselled stone within a one millimetre 'tolerance' on all its six faces. This was described by most as seemingly meaningless at the time, but later regardedas the way in which the ethos of quality was inscribed into working practices. Some saw the milestone of successfully 'squaring the stone' as the basis of progression to more meaningful and technically challenging work. Through the apprenticeship, the masons learned to work at the deliberate and measured pace typical of traditional historic crafts rather than focusing on speed and efficiency (Jalas, 2006).

Doing a 'good job' as a conservation stonemason involved working slowly and cautiously on individual stones that could take months to repair. As was the case for the boat craftsmen in Jalas's(2006) study, the pace of work was dictated by both tradition and material objects; the limestone blocks had to be assessed for the 'grain' of the stone in order to work out the best way to cut it, with the relationship between mason and stone developing as they 'worked through the stone' - 'the most important thing for a stonemason is the connection with the materials, working stone and using traditional mortars'. 
Together, these gave rise to meaningfulness; 'you are protecting the actual art of working a stone by hand'.

The refuse collectors spoke about the 'end of the day' as the completion of a work cycle from which they as a group derived a sense of meaningfulness and daily 'the tipping point' as a time when a team's efforts were officially recognised. The work of the refuse collectors was fast-paced and highly time determined, in common with other forms of manual work (Grossin, 1974). Work was organised in a cycle of often repetitive tasks to be completed during the daily shift. Unexpectedly, materiality featured in refuse collectors' descriptions of meaningfulness in terms of how they viewed the waste they collected and their engagement in a recycling discourse. It was important that the 'waste' was not wasted but rather recycled and they expressed a sense of pride that the plastics, paper and other materials had forward temporal relevance to well-known tangible consumer items, 'I'm actually doing something for the public and for the environment.' Thus, conservation emerged as an important theme in the meaningfulness discourse of both the refuse collectors and the stone masons.

The complexity and variety of tasks among academics, involving teaching, administration and research, gave rise to distinct sub-routines within the socio-temporal ordering of their work, largely configured around the cycle of the academic year. Research work was described as slow, labourintensive and time-consuming, requiring open-ended 'thought-time' (Noonan, 2015). The work sometimes involved devoting time to projects or materials that 'nobody really understood ... when I was doing the research' yet which became a profound source of meaningfulness to the individual as the importance of the research was revealed over time. In a similar way to the stonemasons, the academics talked of their role in teaching their students 'to learn and to be patient with the learning process ... give yourself time to understand things'. The sense of enabling and contributing to students' development and thus handing their knowledge on through the generations was described as a source of meaningfulness for the academics.

\section{Ownership and control of time}

All three occupational groups reported that a sense of control over the way they spent their working time was associated with the experience of meaningfulness. The refuse collectors generally experienced lower levels of autonomy than the academics or the stonemasons. However, between the fixed points at the start of the day when targets were set and the end of the day when the waste was tipped and weighed, they had relative autonomy to organise their time in whatever way they wished, describing themselves as feeling like 'their own boss', 'being left alone to get on and do your job'. In the context of fairly tightly controlled daily and monthly targets, it was this core part of the day that the refuse collectors regarded as meaningful in terms of being able to control the pace and timing of their own work, free from managerial controls, particularly in relation to the routes chosen to collect waste, 'I was working out where I've got to be and in what order and it worked first time'. In a similar way, Bolton (2005) shows how actors can seek out unmanaged organisational spaces to construct their own realities.

The masons derived a sense of meaningfulness from their work through the deliberate control and pacing of their work by using craft based techniques shared within the community of practice that slowed down the speed of production; 'sometimes it's easier and quicker to take shortcuts, but you 
can't, you have to be quite disciplined'. Resistance to the occasional pressures from managers to use more modern techniques in order to complete the job more quickly was justified on the grounds of the primacy of traditional skills; as one said, '[stonemasonry] might even become more meaningful as things become more computerised and technical ... you can't really mass produce for somewhere like this'.

The academics reported far greater temporal control and autonomy than the other two groups, albeit within the constraints posed by teaching timetables; 'at least on paper you have more freedom to do your own research and to manage your time and that is a very, very positive thing'. This autonomy enabled them to spend time on their own research agendas, but conversely oftenalso meant working very long hours due to the diffuse boundary between self and occupation, 'I see myself as a big part of what I do and what I deliver is me.' This freedom to spend at least part of their working lives working at their own pace on projects they had chosen was associated with experienced meaningfulness, 'to do research well, it's a creative kind of thing and you can only be creative if you've got the time and inclination to play in the sandpit really'.

\section{Phenomenological time}

Responses indicated that the experience of work as meaningful could arise in any occupation, but was temporally episodic and transitory rather than permanent and ongoing. These experiences of meaningfulness were consistently characterised by the perception of temporal interconnections. Common to these reported moments of meaningfulness was a sense of the individual looking back over their completed work both in the immediate and the distant past, while recognising its significance and wider contribution. In the most profound examples of this, the temporal locus of the work experience, while anchored in the present, held simultaneous historic and future references (Tsoukas, 1994). For example, one of the masons explained his role in completing a major project on the cathedral:

That was quite a big thing in our job to say that I've actually been a part of this whole thing, when something is completed you can stand back and say "I built that" ... we can put our banker mark [mason's signature] into the stone when it goes into the building. When they take it out in 400 years' time, it might still have my mark on it and they can say, "Oh, he did $i t^{\prime \prime}$.

In this description, the mason situated his present actions and contribution within a broad temporal landscape that stretched hundreds of years into both the past and the future. Similarly, one of the refuse collectors talked about the meaningfulness of his work in relation to past and future generations, locating his work within an intricate rhythm of material use, disposal and reuse:

Every day you are doing something for the environment .... I still feel it's important that I contribute [by recycling] because l've got grandchildren who are going to have grandchildren. It affects [the] next generation coming up. If our great grandfathers had had these visions years ago, we wouldn't be in these positions.

The academics explained how the meaningfulness of their work arose from the investment of time 
into research whose benefits could only be realised in a potential future and not the present. Meaningfulness was ascribed in hindsight on reflection through a process Schutz has described as symbolic systems of relevances (Muzzetto, 2006: 15-17):

Twenty years ago I was working on materials called [name] electrics materials, nobody really understood them, now those materials are on the front screen of every iPhone because they take the electricity from your finger ... but nobody thought of that when I was doing the research. So I cannot tell whether my research is going to have any applications or not. I know it doesn't immediately, but it could do in the future and you have to do the research that doesn't as well as the research that does.

\section{Meaningless work}

Interviewees were asked about times when their work appeared meaningless. All respondents could recall instances when their work seemed meaningless and participants talked of three temporal factors that gave rise to this: being 'stuck in the moment' wasting time undertaking tasks with no wider temporal horizon; lack of temporal autonomy or control over the use of time; and temporal conflicts, manifest as either competing demands within the job itself or tension between work and personal time.

For the academics, being 'stuck in the moment meant time spent doing bureaucratic tasks lacking a broader temporal reference. One said, 'there are timeswhen I am doing utterlypointless things at this university"'. Several spoke about having to undertake tasks that took them away from what they perceived to be the main focus of their role, but being prepared to tolerate them as long as they connected to 'the bigger picture'. One said: 'I am pretty good with tedious work as long as it's got a larger meaning, a proper significance in that I am doing it because it's helping students to develop...'. When this wider temporal horizon was absent some described their work as 'pointless' and 'without purpose'. Pointless use of time was also cited by the refuse collectors. One explained his frustration at how some streets would 'never get any better' no matter how long they worked, 'it didn't matter what you did, it was a $\mathrm{s}^{* * *}$ hole 10 minutes later or half an hour later.' In the stonemasons' descriptions of meaninglessness, time was seen to be wasted where their masonry work was repetitive and part of a larger process where no long term output was visible, or there was no connection to traditional ways of working, thus divorcing the experience of work from the temporal orderings suggested through the material agency of the stones or a sense of connection to the past (Jalas, 2006) One stonemason described the boring experience of being stuck doing repetitive masonry tasks - such as 'mastering mouldings' - which appeared to have no end ... 'when you're working sometimes and when there's an end, there's something to look forward to. If there's nothing to look forward to, it's very hard'.

Lack of temporal autonomy and the sense of not having control over how to allocate time to do one's job also led to meaninglessness for all three groups, usually associated with pressures from managers over how to spend working time. This arose for the stonemasons when they were asked to speed up their work using what they perceived as inappropriate modern tools and techniques to speed up their work, and for the refuse collectors when they were asked to slow down in order to adhere to safety procedures they regarded as unnecessary, similar to the nurse aides in Lopez's (2006) study of a care 
home forced to violate official rules to complete their work on time. In the case of the academics, this arose through processes of work intensification and the growing demand to spend more time on 'administrative aspects' of the job, which was perceived as stealing time from the more meaningful work involved in research and teaching. One stated how '[the management] didn't care about me, just work, work, work, I didn't see any long term plan, only short term plans'. In cases such as these, respondents talked not only of loss of temporal autonomy but also of intensification and the erosion of meaningfulness, akin to the inauthentic temporality of Heidegger's lost present. Lack of temporal autonomy within the labour process emerged as the factor most closely associated with meaninglessness among all groups and was reminiscent of the loss of control and commodification of time experienced by the call centre workers in Ellis and Taylor's (2006) study.

Conflicting temporalities were manifest in the case of the academics through the tensionsarising from the varied demands of the academic year cycle, conference paper deadlines and bureaucratic requirements. This gave rise to a disordered temporality with competing rhythms resulting in excessive pressure sometimes spilling over into their personal lives to the point where, as one respondent said, 'I haven't got time to live really'. Another said in relation to preparing funding bids, 'I was getting up at 4, 5 o' clock in the morning, just working every minute I could, ignored everything at home, there was nothing left in the freezer. I was very run down and I realised I had worn myself out and I thought, "why am I doing this?" ... there's never enough time' ..., reminiscent of the symbolic temporal sacrifices of the software developers in Jemielniak's (2009) study.

The refuse collectors actively monitored the contested boundary between 'my time' and 'their time'; finishing late was cited as a time when work appeared meaningless; 'yesterday, we didn't finish until $5.30 \mathrm{pm}$.... and you miss out on your family time'; 'I've been [here] two years now and I've lost 23 days' holiday, not through my fault but through the company, and when they don't give you it, they take it away from you and then that's when you resent the company'. Another refuse collector said:

'[The company] wanted me to do a course and it was on my daughter's $18^{\text {th }}$ birthday and the manager said, "You've got to go, there's no option". I said I'd prefer to go to my daughter's birthday which we'd arranged months in advance. He said "do you want to progress within the company or stay as you are?" I've [since] applied for loads of jobs and didn't get them ... I've given up about 13, 14 hours a day to the company and I'm not getting anywhere with it. So from now on, once I finish work that's with my family, that's their time. The company pay me for 8 hours but outside of that is my time'.

As Simpson et al (2014: 763) argue, the idea of time sacrifice as a source of meaning is important in the context of dirty work but when this sacrifice is not recognised, for example in terms of the 'futurty' of promotion or reward, the temporal boundary between 'my time' and 'company time' is brought into sharp focus and work is no longer seen as a source of meaning. In contrast, the masons spoke of using their 'craft' in domestic or leisure settings and gave up weekends to promote the craft at community fairs. Academics talked of 'living the job' as being an inevitable and accepted part of their role. These latter two instances were resonant of the merging of temporal and social boundaries experienced by the mobile hairdressers in Cohen's (2010) study.

\section{Discussion}


In this research on meaningful work across a range of occupations, temporality emerged as a fundamental theme underpinning rich descriptions of meaningful moments. Drawing on phenomenological theories of time, notably the work of Schutz and Mead, we found that in peak experiences of meaningfulness, participants relayed how they inhabit phenomenological timescapes where past, present and future, rather than being ontologically distinct, are all present in temporally transcendent moments in time. Meaningless work, on the other hand, was associated with a restricted, controlled or conflicted temporal landscape.

While the research on meaningful work seems to suggest that some jobs are inherently more meaningful than others (Rosso et al., 2010), our data on the contrary show how individuals in occupations as diverse as stigmatised, craft and professional work, can all experience elements of their work as both meaningful and meaningless. None of the three occupational groups regarded their work as consistently meaningful, but rather meaningfulness emerged as an episodic feature of all roles. Schutz has argued that people turn their attention to some lived experiences rather than others, since every experience refers back to past experiences and the future experiences it anticipates through a system of personally meaningful symbolic and social relevances (Muzzetto, 2006). For all occupational groups, the strongest experiences of meaningfulness arose during celebratory or ritual istic occasions, whether formal as in the case of the masons and the academics, or informal, as in the case of the refuse collectors, which were episodic in nature, represented the culmination of a project, task or period of time and at which the participants looked back, together with significant others, at successful achievements and, in the most powerful cases, projected forward to the future impact of their work. Moments that were temporally bound in the present, such as work tasks perceived as pointless or unnecessary, did not give rise to experienced meaningfulness but were rather perceived as meaningless and 'lost time' (Hoy, 2009).

Hassard's (2000) notion of temporal ordering is also relevant here, as for instance the stonemasons described their role as craftsmen in terms of both ensuring the continuity of historic methods of working in the present (Jalas, 2006), and also into the future as part of a community of practitioners interested in maintaining accepted standards of 'good work' (Muirhead, 2004). The community of practitioners thus involved not just those tangible others around whom the masons worked, but also imagined past and future communities whose views have the same immediate resonance as their current counterparts. The embodied practice of 'working the stone' is therefore situated within a timescape that extends as much as 800 years into the past and future and reflects Jalas's (2006) notion of the agency of material objects. Similarto Jalas's (2006: 346) description of traditional crafts in the context of wooden boats, the stonemasons de liberately sought a 'self-artistry of slowness' in working to the standards and methods of prior generations of masons.

Ostensibly, refuse collecting might be viewed as 'dirty work' with limited scope for meaningfulness and foreshortened time-horizons. However, it emerged that the refuse collectors also perceived their work as meaningful within the context of an extended timescape; in this case, though, the projection was forward to the impact of their work on future generations and the preservation of the environment. In a similar way to the butchers in Simpson et al.'s (2014) study, the refuse collectors resisted devaluation and derived a sense of dignity and moral worth from an ostensibly alienating occupation through pride in their contribution and a collective sense of camaraderie. While the 
masons viewed working slowly as the mark of quality, the refuse collectors saw working quickly and getting back to the depot early as signifying a job 'well done', enabling them to return home to 'their time'. 'Lost time', conversely, was personal time given to the employer in the form of overtime. This is illustrative of the potentially conflicted nature of the processes through which a sense of meaningfulness may be derived. Whilst the refuse collectors found meaning in the content of their jobs, they also acknowledged wider sources of meaning from their personal lives reflecting a hitherto unresolved tension between different domains of meaningfulness. Nonetheless, rather than work engendering simply negative perceptions such as stigma, sacrifice and self-denial, the lens of temporality shows that refuse collectors were able to identify times when their work itself was meaningful in similar ways to the other two groups. It also ill ustrates the varying temporal structures and time pacing of jobs referred to by Bergmann (1992) and the negotiated boundary between individual and organisational time described by Hassard (2000). This same boundary was, for the stonemasons, more ambivalent and fluid, with many also choosing to use their craft in domestic settings away from work, thus fusing their personal and occupational identities in similar ways to the academics. Like the others, the academics experienced moments of awareness of the meaningfulness of their work when reflecting back on what they had achieved, but also times when their work appeared meaningless when it involved 'wasting time' on activities regarded as unnecessary or unproductive.

There was a strong association between perceived lack of autonomy and temporal control and meaninglessness. For all three groups, having a temporal pace imposed on their work with which they disagreed eroded a sense of work being meaningful. For the academics, this involved circumscribing their freedom to decide how to spend their time, for the masons it was being asked to work too quickly using modern materials and techniques and for the refuse collectors it was being asked to work too slowly to ensure adherence to what were perceived to be unnecessarilystrict safety guidelines. These perceptions appeared to go beyond simplya sense that time was being wasted, to suggest that it was being 'stolen' from more meaningful work or, in the case of the refuse collectors, from 'their' time The significance of temporal control at once symbolises and extends perceptions of autonomy within the labour process more widely, and is suggestive of a challenge posed by workers at both the individual and the collective levels to the commodification and management of time as an instrument of capitalist control structures.

It appears from all three groups' descriptions that rarely is meaningfulness experienced merely in the moment, but rather emerges from an appreciative or reflective act in which the significance of the moment is perceived within a wider timescape. The very nature of these reflected moments as meaningful means they are untypical and infrequent events in work that are 'peak' experiences (Koltko-Rivera 2006). It is in this process that the timescape in which meaningfulness is experienced becomes a-linear and discontinuous, and includes an underlying sense of time passing or time having passed. Taken in isolation, the moments experienced in the 'now' may lack meaningfulness. Their meaningfulness emerges from a temporal recontextualisation, both historically in light of events past and in terms of what Hoy (2009) terms the 'futural', the perceived future significance of events not yet come. It is suggested this asymmetrical sense of time is characteristic of experienced meaningfulness.

\section{Conclusions}


The study is one of the few empirical investigations into the experience of meaningful work from a qualitative, sociological perspective. Contrary to psychological studies that measure 'experienced meaningfulness' seemingly as a steady state, these findings show that meaningfulness arises in 'transcendent moments in time' rather than as a sustained state of being, reminiscent of Ramo's (2004) notion of kairos, or timely moments. It is further shown that these moments are accessible to workers in three distinct types of work. These moments are imbued with a sense of the coming together of the practice of work, reflection on that practice and the sense of a job well done, connection with others, coupled with an awareness of the significance of work in its historical and future context. The moments are also illustrative of the 'vivid present' (Schutz, 1962), moments in the present that acquire significance in relation to their history and projected future. They al so occur only after a job is completed, when the individual casts an 'existential gaze' on the horizon (Mei, 2006), 'looking back' or 'standing back' to see their contribution in a wider temporal and spatial plane. Meaninglessness, on the other hand, is associated with the 'lost present' (Hoy, 2012), a temporal landscape lacking in past and future horizons. The experience of work as meaningful and transcendent thus refers not merely to the transcendence of self-interest, but al so the transcendence of time. Frankl (1962) has argued that humans have an innate drive to seek meaning in their lives; meaningfulness may be a personal experience, but it also arises in a social and collective context through shared temporal rhythms co-created with colleagues, the work itself, and material objects. Efforts within the labour process to impose temporal regimes on workers are generative of negotiated orders of temporality, of a 'lost present', or of conflicted, disrupted temporalities that mobilise individuals' resistance in the face of a sense of meaninglessness.

This study does have a number of limitations. We only draw on the experiences of workers in three occupational groups. More research that expands on the link between temporality and meaningfulness for instance in other cultural settings and using other methodologies, such as observational studies or quantitative approaches involving a broader range of participants would be welcome. Given that most research has taken place within the psychology field, there is a dearth of sociologically-oriented studies that have focused on meaningful work and therefore a lack of theorisation in the area. Studies that develop the existing focus within sociology on the meaning of work to interrogate further the ontological status of meaningfulness from a sociological and cultural standpoint would help to generate deeper insights. Finally, research that explores the processes by which work is rendered meaningful to individuals alongside the consequences of meaningfulness for workers and for employers would advance an understanding of the locus of meaningfulness within wider models of organisational behaviour. Research that explores in greater depth the nature and form of 'transcendent moments in time' would be welcome.

Despite these limitations, this study is one of only relatively few qualitative studies that focuses on meaningful work and the only identified empirical study that seeks to link debates on meaningful work with notions of temporality. As such, the insights into 'transcendent moments in time' as one of the cornerstones of the experience of work as meaningful helps to advance knowledge on this important topic.

\section{References}


Ballard D I and Webster S P (2009) Time and time again: the search for meaning/fullness through popular discourse on the time and timing of work. Kronoscope 8(2): 131-145.

Bergmann W (1992) The problem of time in sociology: an overview of the literature on the state of theory and research on the 'sociology of time', 1900-1982. Time and Society 1(1): 81-134.

Bernard H R and Ryan G W (2010). Analyzing Qualitative Data: Systematic Approaches. London: Sage

Bolton S C (2005) Emotion management in the workplace. Basingstoke: Palgrave Macmillan.

Budd J (2011) The Thought of Work. Ithaca: ILR Press.

Cavendish R (1982) Women on the Line. London: Routledge and Kegan Paul.

Cottrell W (1939) Of time and the railroader. American Sociological Review, 4: 190-198.

Cohen R L (2010) Rethinking 'mobile work: boundaries of space, time and social relation in the working lives of mobile hairstylists' work. Work, Employment and Society 24(1): 65-84.

Cox J and Hassard J (2007) Ties to the past in organization research: A comparative analysis of retrospective methods. Organization 14(4): 475-497.

Cunliffe A Luhman J and Boge D (2004) Narrative temporality: implications for organizational research. Organization Studies 25(2) 261-286.

Davies K (1994) The tensions between process time and clock time in care-work. The example of day nurseries. Time and Society 3(3): 277-303.

Davis D S (1984) Good people doing dirty work: a study of social isolation. Symbolic Interaction 7(2): 233-247.

Ellis V and Taylor P (2006) “You don't know what you've got till it's gone”; re-contextualising the origins and development of the call centre'. New Technology, Work and Employment 21(2): 107-122.

Flaherty M and Fine G (2001) Present, past and future: conjugating George Herbert Mead's perspective on time. Time and Society 10(2/3): 147-161.

FrankI VE (1962) Man's Search for Meaning: An Introduction to Logotherapy. Boston: Beacon Press. Grossin W (1974) Time orientation and social class: a correction. Journal of Abnormaland Social Psychology 62: 141.

Harison C.(2000) The rise and decline of a revolutionary space: Paris' Place de Greve and the Stonemasons of Creuse, 1750-1900. Journal of Social History 34 2: 403-436.

Hassard J (2000) Images of time in work and organisation. In: Grint K (ed) Work and Society: A Reader. Cambridge: Polity Press.

Hoy D C (2009) The Time of Our Lives: A Critical History of Temporality. Cambridge: MIT Press. Jalas M (2006) Making time: the art of loving wooden boats. Time and Society 15(2/3): 343-363. 
Jemielniak D (2009) Time as symbolic currency in knowledge work. Information and Organization 19(4): 277-293.

Koltko-Rivera M (2006) Rediscovering the later version of Maslow's hierarchy of needs: selftranscendence and opportunities for theory, research and unification. Review of General Psychology 10(4): 302-317.

Langley A, Smallman C, Tsoukas H and Van de Ven A (2013) Process studies of change in organization and management: unveiling temporality, activity and flow. Academy of Management Journal 56(1): 1-13.

Lips-Wiersma Mand Morris L (2009) Discriminating between 'meaningful work' and the 'management of meaning'. Journal of Business Ethics 88: 491-511.

Lopez S H (2006) Culture Change Management in Long-Term Care: A Shop-Floor View. Politics and Society, 34 (1): 55-79.

Mei T (2006) Form and figure; Paul Ricoeur and the rehabilitation of human work. Journal of French Philosophy 16(1-2): 57-70.

Muirhead R (2004) Just Work. Harvard: Harvard University Press

Muzzetto L (2006) Time and meaning in Alfred Schutz. Time and Society 15(1): 5-31.

Noonan J (2015) Thought-time, money-time, and the temporal conditions of academic freedom. Time \& Society, 24(1): 109-128.

O'Rand A and Ellis R (1974) Social class and social time perspective. Social Forces, 53: 53-62.

Patton M Q (2002) Two decades of developments in qualitative inquiry. A personal, experiential perspective. Qualitative Social Work 1 (3): 261-283.

Pedersen A (2009) Moving away from chronological time: introducing the shadows of time and chronotopes as new understandings of 'narrative time'. Organization 16(3): 389-406.

Pina e Cunha M (2004) Organizational time: a dialectical view. Organization 11(2): 271-296.

Ramo H (2004) Spatio-temporal notions and organized environmental issues: an axiology of action. Organization 11(6): 849-872.

Rosso B D, Dekas K H and Wrzesniewski A (2010) On the meaning of work: a theoretical integration and review. Research in Organizational Behavior, 30: 91-127.

Routledge C, Arndt J, Wildschut T et al (2011) The past makes the present meaningful: nostalgia as an existential resource. Journal of Personality and Social Psychology 101: 638-652.

Saldana J (2013) The Coding Manual for Qualitative Researchers. London: Sage.

Schutz A (1962) On multiple realities. A. Schutz, Collected Papers: 207-259. The Hague: Martinus Nijhoff. 
Sennett R (1998) The Corrosion of Character. London: W W Norton \& Co Books.

Simpson R, Hughes J, Slutskaya N and Balta M (2014) Sacrifice and distinction in dirty Work: men's construction of meaning in the butcher trade. Work, Employment and Society, advance publication.

Soane E, Shantz A, Alfes K, Truss C, Rees, Cand Gatenby M (2013) The association of meaningfulness, wellbeing and engagement with absenteeism: a moderated mediation model. Human Resource Management 52(3): 441-456.

Sorokin P A and Merton R K (1937) Social time: a methodological and functional analysis. American Journal of Sociology 42 (5): 615-629.

Terkel S (1974). Working. New York: New Press

Thompson E P (1967) Time, work-discipline and industrial capitalism. Past and Present 38: 56-97.

Thompson P and McHugh D (2009). Work Organisations; A Critical Approach (Fourth edition). Basingstoke: Palgrave Macmillan.

Tsoukas H (1994) Refining common sense: types of knowledge in management studies. Journal of Management Studies 31: 761-780.

Warhurst C, Eikhof D R and Haunschild A (2008) 'Out of Balance or Just out of Bounds? Analysing the Relationship Between Work and Life', in CWarhurst DR, Eikhof and A Haunschild (eds) Work Less, Live More? Critical Analysis of the Work-life Boundary, Basingstoke: Palgrave Macmillan. 
Table 1: Demographic Data

\section{Refuse Stone Academics Total \\ Collectors Masons}

\begin{tabular}{lllll}
\hline Total interviews & 15 & 15 & 14 & 44 \\
\hline Gender: Male & 15 & 12 & 7 & 34 \\
Gender: Female & 0 & 3 & 7 & 10 \\
\hline Age: below 18 & 0 & 1 & 0 & 1 \\
Age 18-29 & 5 & 7 & 1 & 13 \\
Age: $30-39$ & 0 & 1 & 2 & 3 \\
Age 40-59 & 7 & 6 & 9 & 22 \\
Age 60+ & 3 & 0 & 2 & 5 \\
\hline Tenure: less than one year & 0 & 2 & 3 & 5 \\
Tenure: 1-5 years & 4 & 6 & 2 & 12 \\
Tenure: 5 years+ & 11 & 7 & 9 & 27 \\
\hline Ethnicity: White British & 14 & 15 & 7 & 36 \\
Ethnicity: White other & 1 & 0 & 6 & 7 \\
Ethnicity: Black other & 0 & 0 & 1 & 1 \\
\hline Working hours: full-time & 15 & 15 & 11 & 41 \\
Working hours: part-time & 0 & 0 & 3 & 3 \\
\hline
\end{tabular}

